\title{
Using the Workload Indicator of Staffing Need (WISN) - Method to model the HR requirements and costs of Health Care Services in Kyrgyzstan
}

\author{
Olav Goetz ${ }^{1, *}$, Jean Olivier Schmidt ${ }^{2}$, Valerie Broch Alvarez $^{3}$, Sandra Blackaby ${ }^{3}$, \\ and Damira Seksenbaeva ${ }^{3}$ \\ ${ }^{1}$ APOLLON University of Applied Science GmbH, Bremen, Germany \\ ${ }^{2}$ GIZ German Corporation for International Cooperation GmbH, Eschborn, Germany \\ ${ }^{3}$ GIZ German Corporation for International Cooperation GmbH, Bishkek, Kyrgyzstan
}

\begin{abstract}
Health Care systems are facing several challenges. The lack of resources, such as health workers, costing and financing are open and urgent questions in Health Care Systems. Tools from HRManagement (e.g. the Workload Indicator of Staffing Need (WISN) method, WHO - HR-Management Tool) and Cost-Accounting can help to improve current financing and further develop healthcare reimbursement systems, such as DRG-Systems. Based on empirical data and interviews with healthcare professionals from multiple healthcare institutions in Kyrgyzstan the WISN method was applied to calculate human resource needs in a new perinatal health centre in Bishkek, Kyrgyzstan. The results of the analysis show that it is possible to calculate the required personal resources using the WISN method. Additionally, WISN can be used to calculate personnel costs. The results also show that in combination with material costs, e.g. from a DRG - Cost - Matrix, such as the G-DRG-Report Browser, it is possible to calculate the total costs of healthcare services and to use this as the basis for the reimbursement system. WISN in combination with additional Cost-Accounting systems is a good way to calculate the total costs for an intervention in a healthcare institution, e.g. a hospital. These tools can help to make financing in healthcare more transparent and efficient.
\end{abstract}

Key words - Workload Indicator of Staffing Need (WISN), HR Management, HR Calculation, Costing, Diagnosis Related Groups (DRG), Health Care Reimbursement.

\section{Introduction}

Health Care Systems are facing several challenges. The lack of resources, such as health workers, costing and financing are open and urgent questions in healthcare systems. Additionally, healthcare systems can be characterised by several interdependencies with several factors affecting healthcare. On the one hand, the financing is affected by e.g. the revenues and the structure and mechanisms of health financing, the organisational structure of the insurance system and other sources of financing. On the other hand, there are the costs of

\footnotetext{
*Corresponding author: olav.goetz@apollon-hochschule.de
} 
services, which among other things are dependent on the materials and supplies used in the provision of healthcare service, the processes, human resources involved and the quality and treatment standards. Figure 1 shows a simplified model of the interdependencies in healthcare systems.

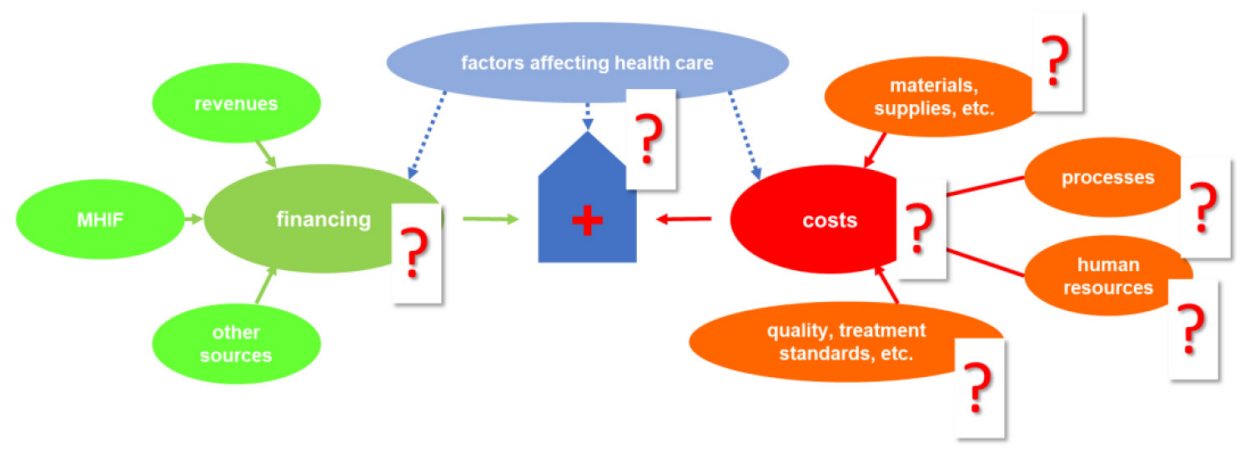

Figure 1. Model of interdependencies in Health Care Systems (simplified). Source: own.

These challenges need to be addressed and tools from HR-Management and CostAccounting can help to improve financing of healthcare services and provide substantial input to further develop healthcare reimbursement systems, such as DRG-Systems [1-4]. The Workload Indicator of Staffing Need (WISN) method, WHO - HR-Management Tool [5-7], can support the process of developing good reimbursement systems. Regarding the different challenges and interdependencies indicated above WISN is suitable in several ways. WISN as a HR-Management Tool is especially useful regarding staffing, task shifting or costing. Additionally, due to WISN's [5] structured approach, which will be explained later, this method can help to improve processes and support process management as well as improving quality and support the definition of treatment standards. The following Fig. 2 indicates where WISN might fit in.

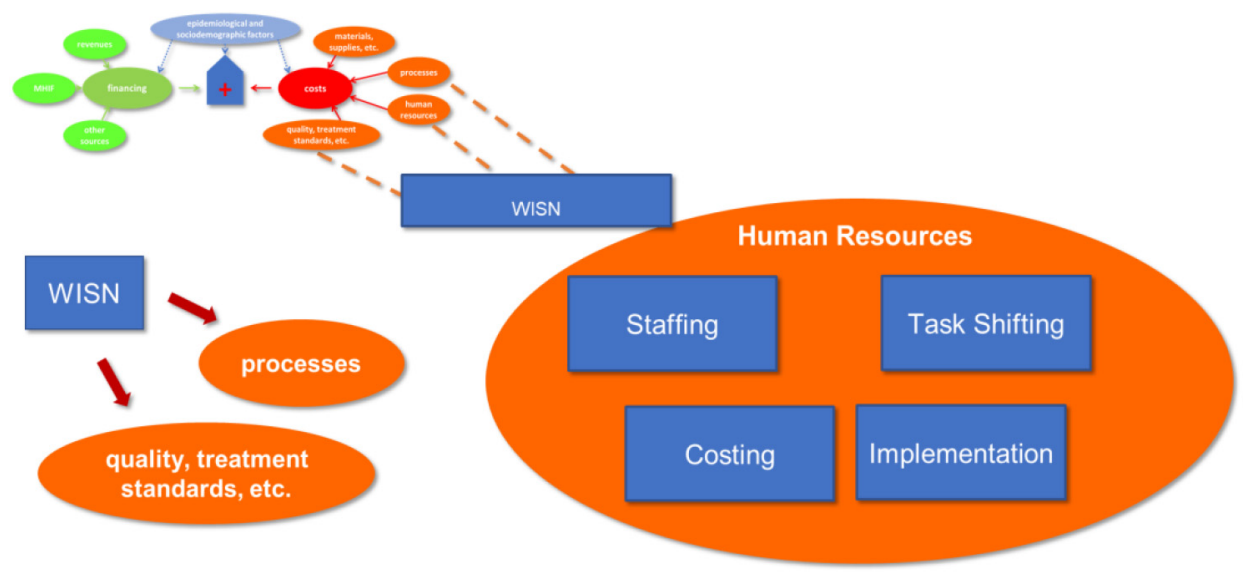

Figure 2. Where does WISN fit? Source: own. 


\section{Material and methods}

\subsection{Methods - Workload Indicator of Staffing Need (WISN)}

There are several different methods and possibilities for calculating HR and workforce requirements. Five commonly used methods for nurses are the professional judgement approach, the nurses per occupied bed method, acuity-quality method, timed-task/activity approach and regression-based systems [8-10]. All of these methods have their advantages and disadvantages $[8,9]$. One essential aspect is that, for example, the population-to-staff-ratios, facility-based staffing standards (quantity of nurses/doctors for a health centre), resource-bedratios fail to take the wide local variations in the demand for services and the workload into account. A systematic way to make staffing decisions is needed. The Workload Indicators of Staffing Need (WISN) method is such a HR management calculation tool and might be beneficial to overcome the above-mentioned challenges.

The Workload Indicators of Staffing Need (WISN) [5] is a method using activity analysis (activity standards) and measures of utilisation and workload to determine staffing requirements. WISN calculates how many health workers of a particular type are required to cope with the workload of a given healthcare facility. Additionally, the method assesses the workload pressure of health workers in that facility. The advantage of WISN is that the method takes into account the differences in the service provided and the complexity of care in different facilities. For an in-depth description of WISN see the WISN User Manual [5]. WISN has been developed by the WHO [5, 7] and is widely used [6]. The following Table 1 provides an overview of selected WISN studies carried out worldwide.

Table 1. Selected literature on WISN.

\begin{tabular}{|c|c|c|}
\hline Year & Authors & Title \\
\hline 1998 & Shipp JP & $\begin{array}{l}\text { Workload indicators of staffing need (WISN): a manual for } \\
\text { implementation. [7] }\end{array}$ \\
\hline 1999 & Ozcan S, Hornby P & $\begin{array}{l}\text { Determining Hospital Workforce Requirements: A Case } \\
\text { Study [11] }\end{array}$ \\
\hline 2003 & Hossain B, Alam SA & $\begin{array}{l}\text { Likely Benefit of Using Workload Indicators of Staffing } \\
\text { Need (WISN) for Human Resources Management in the } \\
\text { Health Sector of Bangladesh [12] }\end{array}$ \\
\hline 2008 & Mugisha JF, Namaganda G & $\begin{array}{l}\text { Using the Workload Indicators of Staffing Needs (WISN) } \\
\text { Methodology to assess work pressure among the nursing } \\
\text { staff of Lacor Hospital [13] }\end{array}$ \\
\hline 2010 & World Health Organization & Workload Indicators of Staffing Need: User's Manual [5] \\
\hline 2013 & $\begin{array}{l}\text { McQuide P, Kolehmainen- } \\
\text { Aitken R-L, Forster N }\end{array}$ & $\begin{array}{l}\text { Applying the workload indicators of staffing need (WISN) } \\
\text { method in Namibia: challenges and implications for human } \\
\text { resources for health policy [14] }\end{array}$ \\
\hline
\end{tabular}




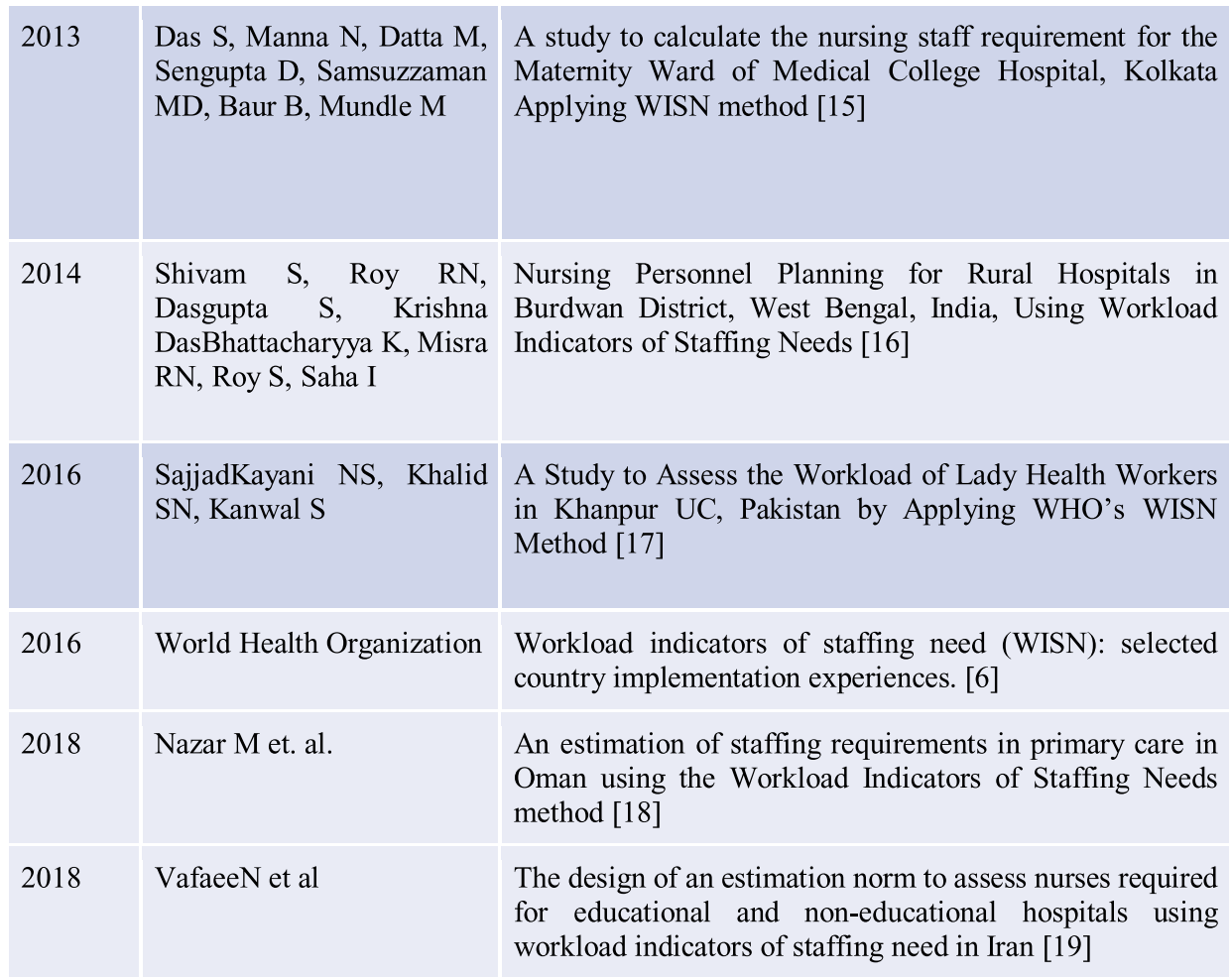

WISN uses several steps to calculate the HR requirement. There are 8 steps to be followed [5]:

- determining priority cadre(s) and health facility type(s)

- estimating available working time

- defining workload components

- setting activity standards

- establishing standard workloads

- calculating allowance factors

- determining staff requirements based on WISN

- analysing and interpreting WISN results.

All these steps require further analysis, in some cases extensive data collection, in order to be able to use them in the context of a WISN study. For a detailed description of the procedure, please refer to the manual [5].

\subsection{Materials}

Based on empirical data, workshops and interviews with healthcare professionals from multiple healthcare institutions in Kyrgyzstan the WISN method was applied to calculate human resource requirements in a perinatal healthcare provider in Bishkek, Kyrgyzstan. The WISN study was conducted from December 2017 until May 2018, with additional work partly continuing after May 2018, which is not included in the calculation and results presented below.

Using the HR requirement calculation, the personnel costs were calculated and combined with the material costs, calculated using the DRG-Cost-Matrix of the German DRG-System 
(G-DRG-Report-Browser) [20, 4]. These calculations were compared with the reimbursement of the intervention based up on the national reimbursement system in Kyrgyzstan.

\section{Results}

The results of the analysis show that it is possible to calculate the required personal resources using the WISN method. Figure 3 combines the calculations based on the first seven steps of a WISN HR resource calculation. It can be seen that, based on the assumptions made during workshops and interviews with the experts involved, three different health cadres [(i) doctors, (ii) nurses and (iii.) health technicians] could be identified. These health cadres would additionally have different available working times (AWT) and different annual workloads, depending on the three different patient groups, identified in the WISN study, viz. (x) high risk patients, (y) medium risk patients and (z) low risk patients. These numbers can be found in the upper area of Fig. 3. In total, based on the assumptions made, the total number of staff needed for the each of the different staff categories is (i) 182 doctors (181.64 doctors), (ii) 136 nurses (135.61 nurses) and (iii) 32 health technicians (31.30 health technicians).

Apart from calculating the total number of required staff, WISN can be used to calculate personnel costs, which are the highest share of costs in healthcare institutions. To calculate the total costs and the costs per case, the costs based on the WISN calculations on the one hand and the costs for cost-categories four to eight of the DRG Cost-Matrix on the other hand were used. As a basis for the DRG calculation the G-DRG "O60A" (Vaginal delivery with several complicated diagnoses, at least one difficult, pregnancy duration up to 33 completed weeks or with complicated constellation) and the DRG INPUT from the G-DRG-Browser 2017 was applied [20]. The cost categories four to eight in the DRG-Cost-Matrix are more or less related to material costs, whereas cost categories one to three are related to personnel costs. These personnel costs were calculated based on WISN staffing requirements multiplied by the assumed average salary per month in SOM in 2017 (doctors: 15,000,- SOM; nurses: $12,900,-$ SOM and health technicians 10,500,- SOM). The DRG cost categories four to eight were included in the calculation as proportional costs (as a percentage) of these cost-categories. For the "O60A" the percentage of the cost-categories 4-8 is approximately $43.92 \%$. Thus, the total costs can be calculated as the sum of "Staffing Costs calculated by WISN" plus the "Costs for categories 4-8 of DRG Calculation" as it is shown in Figure 4. As mentioned above, the total costs for categories 4-8 of DRG Calculation are calculated as a percentage (one patient $=$ one DRG, average costs of one DRG for category 4-8 = Costweight * Base Rate * Percentage of category 4-8) and are in total 4,965.68 SOM. The assumed Costweight is 1.512 as it is the Costweight for the "O60A", the percentage as the share of the cost-categories 4-8 (approximately 43.92\%) and the assumed Base Rate is the 2017 valid DRG Base Rate in Kyrgyzstan in SOM (7,478 - SOM). The total costs (per year) are now calculated using the number of staff needed multiplied with the salary of the health cadre per year plus the costs per case (costs for categories 4-8 of DRG Calculation) multiplied by the assumed numbers of cases of 8,000 per year. This makes a total of $97,356,021.71$ SOM (total costs $=180,000.00 * 181.64+154,800.00 * 135.61+126,000.00 * 31.30+8,000 *$ $4,965.68)^{1}$ and $12,169.50 \mathrm{SOM}$ per case. Figure 4 presents an approximate overview of the calculation concept and the results for the costs calculation. Taking the figure for the currency rate of $1 \mathrm{EUR}=82.91 \mathrm{KGS}(31 / 12 / 2017), 97,356,021.71 \mathrm{SOM}$ for assumed 8,000 deliveries in 2017 would be equivalent to 1,174,237.39 EUR (per case: 146.78 EUR).

\footnotetext{
${ }^{1}$ Deviating values can result from rounding, since the exact values were used in the Excel calculations and the values used in the equation are rounded values.
} 


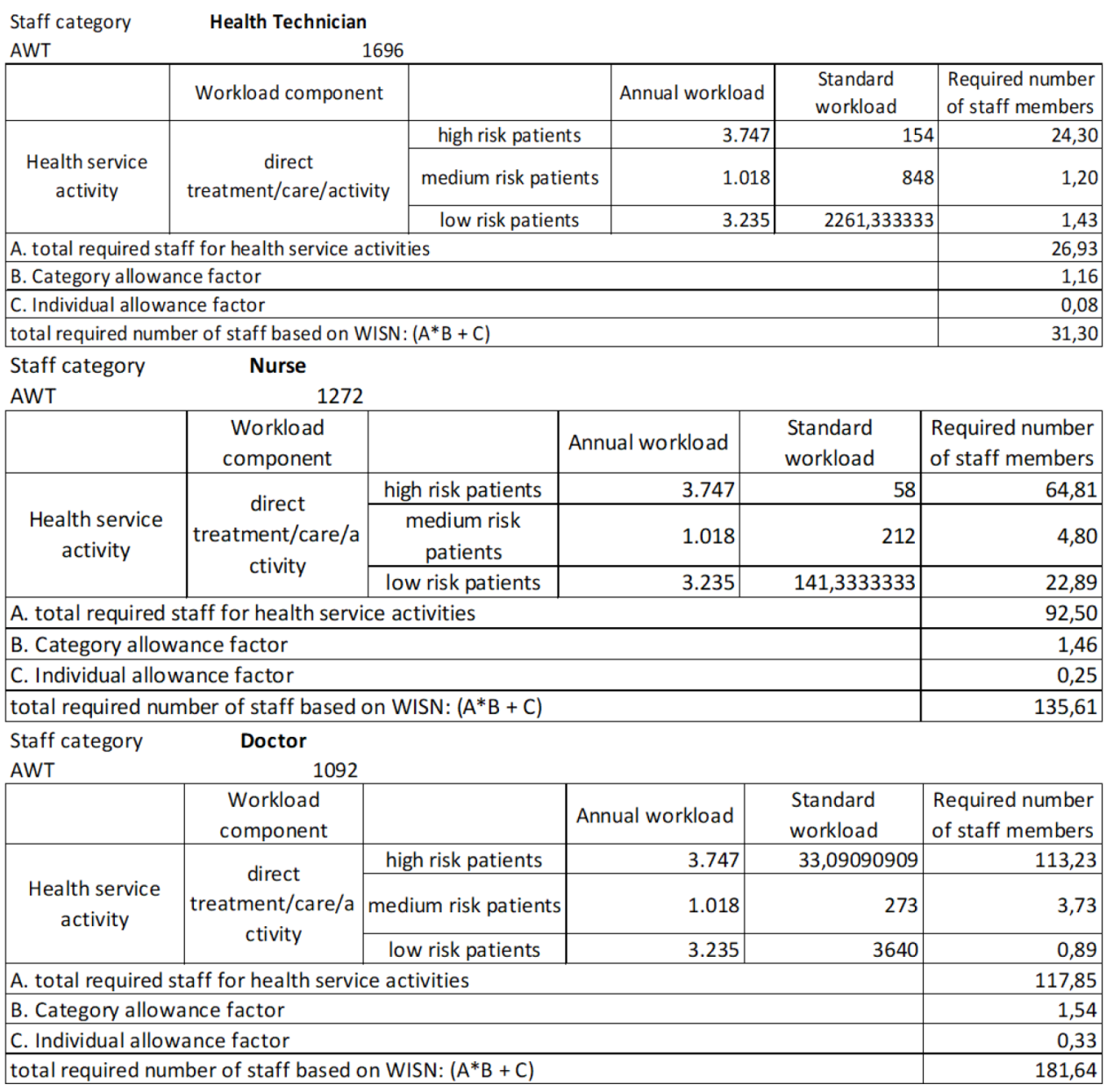

\begin{tabular}{|c|c|c|r|}
\hline \multicolumn{3}{|c|}{ Staff requirements based on WISN method } \\
\hline Staff Category & Doctors & Nurses & Health Technicians \\
\hline Number & 181,64 & 135,61 & 31,30 \\
\hline
\end{tabular}

Figure 3. Calculating Staffing Requirements. Source: own.

Apart from calculating the costs using a combination of WISN and the corresponding DRG cost categories from the G-DRG Browser, it was possible to apply different scenarios regarding the risk structure of patients. So, a distinction between three scenarios was calculated, named as Scenario 1 (low high risk), Scenario 2 (baseline) and Scenario 3 (high high risk) with a distribution of the different patient categories as shown in Fig. 5. Depending on the risk 


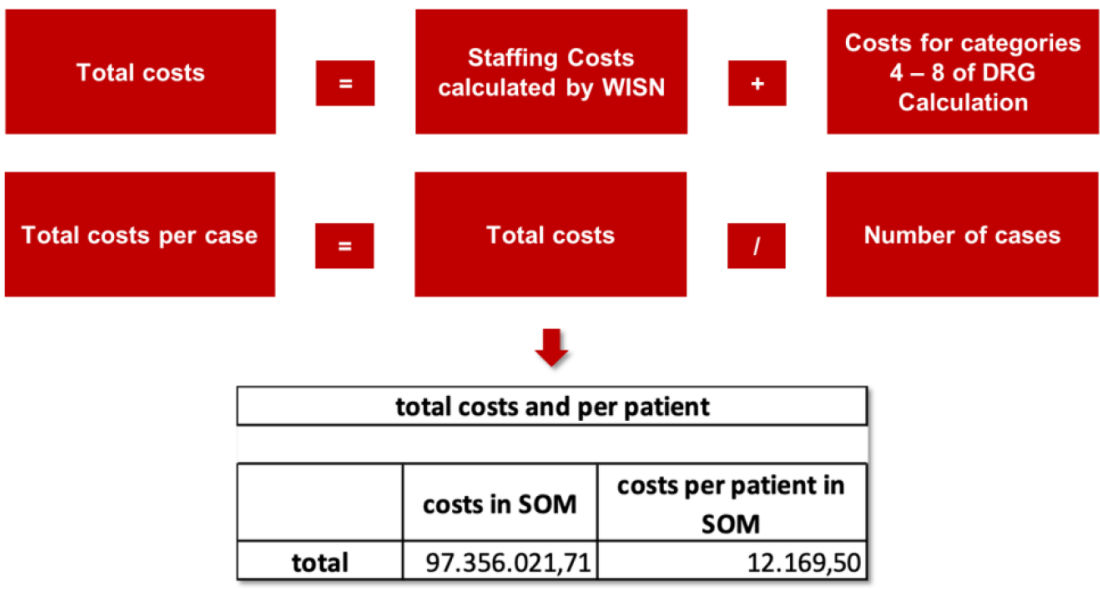

Figure 4. Calculating Costs. Source: own currency rate: 1 EUR $=82.91$ KGS (31/12/2017); https://bankenverband.de/service/waehrungsrechner/ (25/02/2021).

structure of the patient categories the WISN calculation leads to different resource requirements and subsequently to other total costs and costs per patient. As shown in Fig. 5 Scenario 3 with more high risk patients total costs result in: 110,162,768.15 SOM (1,328,703.03 EUR) and 13,770.35 SOM (166.09 EUR).

\begin{tabular}{|c|l|r|r|r|}
\hline \multicolumn{2}{|c|}{ Scenario - Number of Cases (Middle Salary Scenario) } \\
\hline \multirow{2}{*}{} & \multicolumn{3}{|c|}{ number of cases } \\
\cline { 2 - 5 } & $\begin{array}{c}\text { Scenario 1 } \\
\text { (low high risk) }\end{array}$ & $\begin{array}{c}\text { Scenario 2 } \\
\text { (baseline) }\end{array}$ & $\begin{array}{c}\text { Scenario 3 } \\
\text { (high high risk) }\end{array}$ \\
\hline \multirow{3}{*}{ patient category } & high risk patients & 800 & 3.747 & 4.800 \\
\cline { 2 - 5 } & medium risk patients & 2.400 & 1.018 & 2.400 \\
\cline { 2 - 5 } & low risk patients & 4.800 & 3.235 & 800 \\
\hline \multirow{2}{*}{$\begin{array}{c}\text { Staff needed based on } \\
\text { WISN per category }\end{array}$} & Doctors & 53,07 & 181,64 & 237,35 \\
\cline { 2 - 6 } & Nurses & 86,76 & 13561 & 146,59 \\
\cline { 2 - 6 } & Health Technicians & 11,83 & 31,30 & 39,86 \\
\hline \multirow{2}{*}{ Costs in SOM } & total & $64.200 .348,28$ & $97.356 .021,71$ & $110.162 .768,15$ \\
\cline { 2 - 5 } & per patient & $8.025,04$ & $12.169,50$ & $13.770,35$ \\
\hline
\end{tabular}

Figure 5. Calculating Staffing and Costing ScenariosCosts. Source: own currency rate: 1 EUR $=82.91$ KGS (31/12/2017); https://bankenverband.de/service/waehrungsrechner/ (25/02/2021).

\section{Conclusions}

It can be concluded that WISN in combination with additional Cost-Accounting systems is an effective way to calculate the total costs for an intervention in a healthcare institution, e.g. a hospital. The study and the results also show, that in combination with material costs, e.g. from a DRG - Cost - Matrix, such as the G-DRG-Report Browser, it is possible to calculate the total costs of healthcare services and to use this as a basis for the reimbursement system. 
Nevertheless, it should be noted that the WISN study presented here was conducted as a very preliminary pilot study to test the suitability and applicability of WISN as a method to calculate staffing requirements. Cost calculations based on the G-DRG System were added to test the suitability and applicability of the combined approach of calculating personnel costs based on WISN and the other cost categories, mainly the material costs, based on the remaining DRG costs. The results presented above should be interpreted with caution. It is not proven, that the cost structure of healthcare services in general in Kyrgyzstan and of the DRG ("O60A") on which this analysis is based is comparable to the cost structure in Germany, which is the basis for the G-DRG Browser Matrix. Therefore, the cost results might be higher due to additional spending during the provision of healthcare services. Additionally, the question of further funding and the level of total cost coverage of a remuneration system are important aspects of healthcare financing, which should be taken into account in more detail.

Nevertheless, WISN and cost accounting tools can help to develop or improve existing reimbursement systems and make financing in healthcare more transparent and efficient. Further research and a comprehensive WISN study in healthcare facilities for all levels of care would be highly beneficial in Kyrgyzstan and many other countries, including in Europe. The tendency to exclude nursing personnel costs from a DRG-based lump sum reimbursement makes the question of how many staff are involved in healthcare provision even more urgent. WISN could help to calculate these resource requirements.

Apart from the beneficial aspects of using WISN that have been mentioned above, there are other very useful "side effects". Following the steps of conducting a WISN study a process analysis is highly relevant and important. This process analysis could be used to improve quality as part of the process management cycle applying additional methods, such as modelling ands simulation. Figure 6 shows how quality could be improved by using WISN and Process Management.

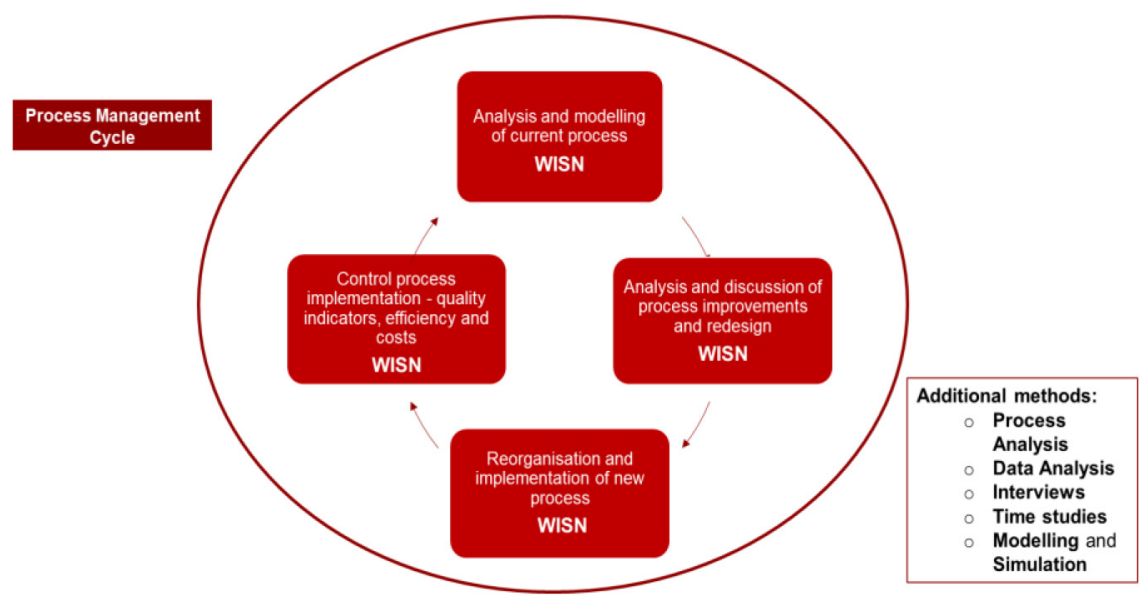

Figure 6. Improving Quality using WISN and Process Management. Source:own.

To summarize, WISN can provide support for evidence-based decisions and support for HR planning. Additionally, WISN is an easy-to-use and widely-used methodology which is suitable for a range of healthcare facilities at primary, secondary and tertiary levels. WISN 
generates data based on need, demand and processes and provides substantial input for cost calculations and therefore provides input for a DRG-System and quality - and process Management. Applying WISN with its several capabilities, will be highly beneficial and of increasing importance in healthcare in the future.

\section{References}

[1] S.S. Tan, A. Geissler, L. Serdén, M. Heurgren, B. Martin van Ineveld, W. Ken Redekop, L. Hakkaart-van Roijen, DRG systems in Europe: variations in costaccountingsystemsamong 12 countries, European Journal of Public Health 24(6), Pages 1023-1028, (December 2014). Available: https://doi.org/10.1093/eurpub/cku025

[2] W. Quentin, A. Geissler, D. Scheller-Kreinsen, R. Busse, Understanding DRGs and DRG-based hospital payment in Europe, in: DiagnosisRelated Groups in Europe Moving towards transparency, efficiency and quality in hospitals, Edited by Reinhard Busse, Alexander Geissler,Wilm Quentin, Miriam Wiley (Eds), Open University Press McGrawHill (2011)

[3] A. Geissler, W. Quentin, D. Scheller-Kreinsen, R. Busse, Introduction to DRGs in Europe: Common objectives across different hospital systems in: Diagnosis Related Groups in Europe Moving towards transparency, efficiency and quality in hospitals, Edited by Reinhard Busse, Alexander Geissler, Wilm Quentin, Miriam Wiley (Eds), Open University Press McGrawHill (2011)

[4] In EK. Kalkulation von Behandlungskosten:Handbuch zur Anwendung in Krankenhäusern gem. 17b KHG, Version 4.0. (October 2016)

[5] World Health Organization. Workload Indicators of Staffing Need: User's Manual, Geneva: WHO Press (2010)

[6] World Health Organization. Workload indicators of staffing need (WISN): selected country implementation experiences (2016)

[7] Shipp JP. Workload indicators of staffing need (WISN): a manual for implementation. Geneva: World HealthOrganization (1998), (WHO/ HRB/98.2)

[8] K. Hurst, Selecting and Applying Methods for Estimating the Size and Mix of Nursing Teams, A systematic review of the literature commissioned by the Department of Health, Nuffield Institute for Health, (2003). Available: https://www.who.int/hrh/tools/size_mix.pdf (24.06.2021)

[9] K. Hurst, Selecting and Applying Methods for Estimating the Size and Mix of Nursing Teams. Main Report (2002). Available: https://www.who.int/hrh/documents/hurst_mainreport.pdf (24.06.2021)

[10] J. Kutscher, Personalbedarfsberechnung aus Leistungseinheiten, Anhaltszahlen und Arbeitsplatzbesetzungen. Available: https://www. arbeitszeitberatung.de/fileadmin/pdf-publikationen/pub96.pdf (24.06.2021)

[11] S. Ozcan, P. Hornby, Determining Hospital Workforce Requirements: A Case Study. Human Resources for Health Development Journal (HRDJ). September - December, 3(3): 210-20, (1999)

[12] B. Hossain, S.A. Alam, Likely Benefit of Using Workload Indicators of Staffing Need (WISN) for Human Resources Management in the Health Sector of Bangladesh. World Health Organization (2003)

[13] J.F. Mugisha, G. Namaganda, Using the Workload Indicators of Staffing Needs (WISN) Methodology to assess work pressure among the nursing staff of Lacor Hospital. Health policy and development 6, (April 2008) 
[14] P.A. McQuide, R.L. Kolehmainen-Aitken, N. Forster, Applying the workload indicators of staffing need (WISN) method in Namibia: challenges and implications for human resources for health policy. Human Resources for Health 11(64), (2013)

[15] S. Das, N. Manna, M. Datta, D. Sengupta, M.D. Samsuzzaman, B. Baur, M. Mundle. A study to calculate the nursing staff requirement for the Maternity Ward of Medical College Hospital, Kolkata Applying WISN method. IOSR Journal of Dental and Medical Sciences (IOSR-JDMS) 8(3), PP 01-07, (Jul.- Aug. 2013)

[16] S. Shivam, R.N. Roy, S. Dasgupta, K. Das Bhattacharyya, R.N. Misra, S. Roy, I. Saha. Nursing Personnel Planning for Rural Hospitals in Burdwan District, West Bengal, India, Using Workload Indicators of Staffing Needs, JHEALTH POPUL NUTR 32(4), 658-664 (Dec2014)

[17] N.S. Kayani, S.N. Khalid, S. Kanwal. A Study to Assess the Workload of Lady Health Workers in Khanpur UC, Pakistan by Applying WHO's WISN Method. Athens Journal of Health (March 2016)

[18] N. Mohamed, A. Al-Qasmi, S. Al-Lamki, M. Bayoumi, A. Al-Hinai, An estimation of staffing requirements in primary care in Oman using the Workload Indicators of Staffing Needs method, East Mediterr Health J 24(9), 823-829, (Dec2018), DOI: 10.26719/2018.24.9.823

[19] A. Vafaee-Najar, M. Amiresmaeili, M. Nekoei-Moghadam, S.S.Tabatabaee, The design of an estimation norm to assess nurses required for educational and non-educational hospitals using workload indicators of staffing need in Iran, Human Resources for Health 16(42) (2018)

[20] In EK. G-DRG-Report-Browser 2017, https://www.g-drg.de/ (28.06.2021) 